\title{
HISTORIC IDENTITY TRANSFORMATION IN CULTURAL HERITAGE SITES THE STORY OF ORMAN HISTORICAL GARDEN IN CAIRO CITY, EGYPT
}

\author{
NOHA ABD EL AZIZ \\ Cairo University, Gamaa Street, Giza; Postal Code: 12613, Egypt, E-mail: \\ noos2000@yahoo.com
}

Received: $11^{\text {st }}$ August 2019, Accepted: $14^{\text {th }}$ November 2019

\begin{abstract}
Historical gardens in Egypt witnessed and narrated not only stories of momentous events and influencing dignitaries, but also they hosted rare plants and astonishing architecture. Nowadays, such rich history is losing its identity, which is pragmatic to retain, especially with high rates of urbanization and globalization. Thus, this research focuses on the issue of place identity, as it investigates the impact of socio-economic, political, and spatial forces on formulating the identity of historic gardens in metropolitan cities. Additionally, the research addresses the debate between preserving the garden identity versus approving its evolving. "Orman Garden" is selected, a historic botanical garden in Cairo City, Egypt, to examine the transformation of its identity starting from 1873 till 2019. Research methods include historical researches, a field survey, and interviews with the garden administration staff, current users, and users from old generations. Results declare that the socio-economic forces are the most profound forces behind identity reconfiguring / transformation. Furthermore, the study differentiated between components that were subjected to disfiguration or evolution. The research concludes with recommendations to conserve and revive the lost historical identity while facing current challenges and embracing new demands and trends.
\end{abstract}

Keywords: Orman Garden, Historical Gardens, Cultural History, Urban Identity, historical Identity

\section{INTRODUCTION}

Lucebert, a Dutch poet and an artist several decades ago, said, "Everything of value is vulnerable'. This statement is definitely valid in respect to the natural and cultural heritage, including historic gardens, and cultural heritage (Berjman, 2002). Cultural heritage is the product of people responding to the surroundings they inherit; it embodies the aspirations, skills, beliefs and traditions, and investment of successive generations. It gives distinctiveness, meaning, and quality to places, providing a sense of continuity that connects an individual to the past and conveys a sense of rootedness and identity (English Heritage, 2008; Ouf, 2001). Cultural heritage evokes the city's past and traditions (Lowenthal, 1985). Alexandrakis et al. (2019) divided cultural heritage into two sets; the first set is the Tangible elements as items for religious/cultural/ industrial use or buildings, public gardens, monument, and archaeological sites. The second set is Intangible items as the sense of 
Abd El Aziz N.: Historic identity transformation in cultural heritage sites the story of Orman historical garden in Cairo city, Egypt

identity, space use pattern, expression (oral/manners/custom), believe system, commercial/social/cultural activities. Besides fostering a sense of belonging and attachment, cultural heritage contributes to the city on other levels, as it provides a range of both market and non-market benefits. Additionally, It is a means of place branding and marketing to increase regions' competitive capacities in global markets, and attract tourists and visitors for economic income (Ercan, 2017).

The notion of "Historic Urban Landscape" is the latest contribution to the international discussion concerning the identification and preservation of cultural heritage (Guoping, 2014). The Historic Urban Landscape approach considers the urban historical gardens as a historical layer of natural and cultural values (De Rosa \& Di Palma, 2013), they are valued as an articulation of the past and aggregates of change (Goldfrank, 1991). In 2011, UNESCO stated that a historic urban landscape is "the natural and cultural, tangible and intangible features and elements that interact with each other; it encompasses aspects such as natural system, land use, topography, and geomorphology, ecological structure, vegetation and water, visual structure, social function, architecture and structure, and so on; these elements express and record the view of nature and interest appeal in various cultural models" (Guoping, 2014). While The International Council of Monuments and Site defines a historic garden as " an architectural and horticultural composition of interest to the public from the historical or artistic point of view, as such, it is to be considered as a monument" (ICOMOS, 2018).

Historical gardens are living organisms, experiencing continuous transformation; their characteristics are expressed depending on the concepts of time and space in the city (Beyhan \& Gürkan, 2015). They are rich sources for understanding cultural diversity, creating a sense of place, and building social solidarity and national identity (Ercan, 2017). Consequently design practices of new development in historical sites must be performed cautiously to retain the expression of cultural identity and the community's sense of place attachment (Haruna et al., 2015). For example, in the case of preserving Old San Juan, Puerto Rico, and colonial cities in the United States, it can be seen that the choices of preservation are driven by the sense of national identity to portray a particular image about the origins of culture in these nations. In the conservation plan, they used the historic city buildings for productive cultural experiences tied to the tourist economy and drew attention to certain historical activities in the area (Brill, 2016).

Cultural heritage hinges upon on the idea of identity where the identity is what distinguishes places from others. The notion of urban identity can be seen from different spatial, social, cultural, and economic points of view (Kaymaz, 2013). Understanding the concept of urban identity in historic gardens is crucial. The garden identity reflects the unique socio-economic and cultural components, which is reincarnated in physical shapes and forms (Beyhan \& Gürkan, 2015; Ziyaee, 2018). Unfortunately, the existence and the identity of historical gardens is extensively influenced by two phenomena, urbanization and globalization. Urbanization impacts the existence as it may strangle the garden and transform it to other uses, increase noise levels around it, isolate it from the city, or marginalize its importance compared to the needs of the growing city, while globalization may affect the garden intrinsic character and encourage introducing hybrid/ foreign features, technology or enforcing international trends in its design, disrupting the garden's historical identity.

In developed cities, the pressure for development and other factors resulted in the inability to preserve heritage values, leaving the gardens indefensible, such situation justified demolition or at least negligence. Accordingly, there is a need for special attention to safeguard historical gardens and to understand the concept of identity transformation (Ziyaee, 2018). In the global preservation, academic community, especially in the field of 
preserving historical identities arises a debate between two contradicting concepts, identity evolution and identity lose. What is the difference, what is accepted to be changed, and what affects the integrity unswervingly, causing it to demolish? Many questions in this course are circulating the academic community, with no definitive answers. Questions get ever more complicated in developing countries such as Egypt, where many forces intervene.

Although Egypt hosts numerous historical gardens, in the face of economic, social and political change, the country is struggling like any other developing country to attain the balance between urban development (planned or informal) and preserving heritage cultural. In Egypt, protecting natural heritage is more challenging than built ones (Shetawy \& Dief-Allah, 2013). Negative impacts of urbanization highlighted by Haaland and van den Bosch (2015) are seen in Egypt, including the decrement of areas. Another problem includes degraded quality, linkage, and distribution (Abd El Aziz, 2012). In addition to finding the balance between garden conservation and using them as recreational venues (Abdel Rahman, 2016). Generally, the relationship between conservation and recreation range from mutual support to conflict. Mutual support would occur due to moderate use and suitable activities. Whereas conflict and tension may arise when the heritage value is threatened in order to achieve another important public policy objective or to sustain the place financially (English Heritage, 2008). Finding the balance is critical, especially in cities, where open green spaces are inadequate, and the cultural history identity is in danger.

\section{WHAT IS THE PLACE IDENTITY?}

Generally, Identity can be described as a distinguishing character or personality of an individual, object, or space that allows it to be differentiated from others (Erikson, 1959; Relph, 1976). In the urban context, the urban identity is continuously changing and dynamic; it can naturally shift in time as well as being changed on purpose. It is the result of the interaction between city components (buildings, streets, and squares) and people (Beyhan \& Gürkan, 2015). While place identity is complex in nature and definition (Brill, 2016), it can be defined as special characteristics that provide a place with uniqueness or distinction as a separable entity from other sites (Lynch, 1960; Ujang, 2012). Many scholars explored the components of place identity as Relph (1976), Carmona et al. (2010), Relph (1976) and Ercan (2017). They believe that the physical setting or appearance of the place (land, mountain, and lake or human-made) and the performed activities and how spaces are used (events, situations, and functional patterns) influence the identity. As well, scholars considered the psychological input, which represents the meaning of the place and how people feel about it as a factor formulating the place identity. The place meaning is shaped through experiences and interactions of the users in a place; this includes the recipient's beliefs, ideas, opinions, and emotions (Ercan, 2017). The same results are found in the work of Punter (1991) and Montgomery (1998) as they suggested three elements, manipulating the creation of place identity (forms,/activities/images). Another perspective is presented by Florek, Insch, and Gnoth (2006); they comprehend the place identity and place image as a communication or a language. "Place identity" is viewed as the sender's perspective, whereas "place image" is examined from the receiver's perspective, which varies between individuals; never theless there is a basic image that a majority of receivers assemble based on their shared culture. Beyhan \& Gürkan (2015) confirmed the place identity components by suggesting investigating natural environment (topography/climate/vegetation), society (socio-economic/socio-cultural characteristics), artificial environment (streets/avenues/ squares/monumental architectural buildings). 
Abd El Aziz N.: Historic identity transformation in cultural heritage sites the story of Orman historical garden in Cairo city, Egypt

\section{Place meaning as a component of place identity}

After the emotional bond of people to a physical location, the meaning is formed. Place meanings are not fixed; they can change and be transferred according to both objects and spectators when social values evolve in response to fluctuating patterns of socio-economic organization and lifestyles (Knox, 1984; Handal, 2006). People create place meaning throughout their gradual experience of the place. Not all will experience the urban setting the same; some will have a meaningful connection, while others will not experience any attachment to the site. Place meaning has a tangled relationship with place attachment, where both involve the interaction between physical properties and social attributes (Haruna et al., 2015). Knox \& Pinch (2010) explained that the senders (designers) have the power to shape the space by imposing 'signs' and their ingrained messages, whereas the receivers (users/consumers) perceive the 'received messages.' In 1992, Williams et al. research revealed that the place meaning could be understood through aesthetic meanings, instrumental meanings, cultural meanings, and individual meanings. In a quest to uncover what makes places meaningful, Gustafson (2001), investigated this issue by asking people to list places they considered essential and described what these places meant to them. The meaning was studied around three pillars self, others, and environment, which is consistent with previous studies, Gustafson added distinction, valuation, continuity, and change. Distinction tackles the similarities and differences in comparison with other places. Valuation is the positive or negative evaluation of areas. As for continuity and change of the meaning, it is testing the meaning through time (Gustafson, 2001). In a study by Haruna, et al. (2015) of the meaning in a garden in Malaysia (Padang), results show that the meaning is generated from the residents' daily experiences, childhood memories, the arrangement of important events, local culture, and distinct natural and built properties. In addition to the garden's significant history.

\section{Identity transformation}

As the change in the urban environment is inevitable, the qualities of place identity change and evolve in time with local and global contexts. Relph (1976) claims that identity changes when circumstances and attitudes change. The primary point to be regarded in the urban transformation is to discover the urban identity of the city and to consider the layers formed in time (Beyhan \& Gürkan, 2015). While dealing with historic heritage a question arises, how much should be conserved and what features of place identity should be preserved? What is the difference between losing the identity and evolving? Hence in a space-time continuum where society, technology, culture, and politics change and transform, place identity is constructed and re-constructed constantly by people (Ashworth \& Graham, 2005). Thought the place identity evolves continually, yet intrinsic components and meanings are constant, and they should be preserved while allowing the site to change and adapt to contemporary conditions (Carmona et al., 2010; Ercan, 2017).

Another significant issue is the forces affecting the place identity transformation, especially in the case of historical gardens. Along with globalization and neoliberal urbanism, most of our cities have experienced a postmodern face touched by a global urban identity either by homogenization, standardization or hybridization of other cultures under the brigade of modernism, which threatens the local identity (Pieterse, 2006). It is becoming harder and harder to retain local identities in contemporary societies (Berjman, 2002). Urbanization furthermore threatens the identity of places through man- man intervention in historic places (Kaymaz, 2013; Guoping, 2014). Time, aging erosion, user needs and urban growth with little awareness of the community and municipalities all impact the distinguishing features of places changing their morphology, thus their identity (Abdel 
Rahman, 2016). Moreover, the political institutions and the economic system of a society influence the physical form of spaces (Berjman, 2002). "Commercialization of heritage" is a significant dilemma that harms authenticity and self-identity, it appears when marketing heritage sites as a product according to the demands of the consumer, mainly "tourists" conflicts with the protection of the local identity (Shetawy \& Dief-Allah, 2013; Nasser, 2003). De Rosa \& Di Palma, (2013) added in their research the forces of environmental changes (climate change, pollution, degradation of natural resources). Moreover, ICOMOS-IFLA Committee has noted that there are "poor levels" of appreciation, understanding, information, and care, among responsible institutions and the public towards cultural heritage (Berjman, 2002).

\section{Conserving vs preserving}

Two terminologies circulate the territories of cultural heritage strategies, historic preservation, and historical conservation. Preservation usually tends to pause or understand a resource only from a particular point in time, effectively protecting it from change or evolution. While heritage conservation is more about managing change by strategic management assessment, interpretation, adding value to places, and reinforcing its cultural and natural heritage values to allow people and future generations to use, enjoy and benefit from it (English Heritage, 2008; Fairfax County, 2019). Understanding the dynamic nature of cultural heritage allows us to extricate what ought to be preserved and what should be conserved (Sonia \& Tanasescu, 2013). Selecting a policy to manage cultural heritage sites depends on the site's historical significance, physical condition, proposed use, and intended interpretation; therefore, it demands a meticulous and comprehensive understanding of the status quo and a decisive future vision (National Garden Service, 2018).

Internationally, there are many endeavors dedicated to the conservation and enhancement of the architectural and landscape heritage. One of the leading institutions is the "International Council of Monuments and Sites" (ICOMOS), which was founded in 1965. ICOMOS issues charters to protect historical sites as Venice charter (1964), Florence charter (2008), Newzeland charter (2010), Burra Charter (2013) (ICOMOS, 2018). "Florence Charter" focused on defining and guarding historical gardens. Though it tackles definitions, maintenance, legal and administrative protection, and conservation policies, however, it did not address the issue of heritage evolution; its articles plead to preserve the original designs and formulations, discarding new layers formed by time. Such a rigid methodology faced many hurdles in the implementation process when it stumbled with the various entangled layers of history, leading to vulnerable unprotected historical parks.

\section{MethodS}

This study aims to understand the identity transformation of " Orman Garden," a historical botanical garden, regarding its physical settings, activities, and meanings, in relation to the spatial, political, economic, and historical context of Cairo City, Egypt. This research poses the question of whether the transformation of the garden has caused the loss or the evolution of its identity. Furthermore, the study analyzes the forces affecting the place identity and what can be done to preserve such cultural heritage. This research employs a single-case study method, relies on multiple sources of qualitative and quantitative evidence, involving a mixture of primary and secondary data. Archival documents were used to collect data regarding the history timeline. Direct observations and a survey were carried out during March 2018 to comprehend the users' profiles and how they use the garden. The physical features of the garden were recorded in by a research diary and photos. A face-to-face 
interview was carried out with the garden manager and two members of the maintenance staff (gardeners). The aim of the semi-structured interviews is to grasp the main challenges facing the garden, to identify the significant elements and to collect any historic info about the garden development. The interviewees were asked to suggest solutions to current problems from their point of view. In addition, a total of twenty persons were selected, fourteen are regular visitors and six from old generations (not using the garden now, but used in the 70's and 80s') for 15 minutes each. The first group was picked randomly, taking into consideration that they had visited the garden more than four times in the last year. The fourteen users included nine men and five women ranging from 19 to 35 years old, mostly low to medium income families, and college students. The second groups were two females and four males, age group ranged from 65 to 72 years; they are seniors living in Giza city, or graduates of Cairo University. The year in which the interviewee used the garden was recorded. The aim of the interviews is to understand the value and the meaning of the garden. Questions targeted their perception, attachment, memories, and motives behind visiting the garden in the past. Spatial analyses (by mapping) were used to chronologically track the change in the components of the garden, impacting the total identity. The research limitation lies in the limited sample and the shortage of data regarding the garden history, evolution, and its significance to the users in each period.

\section{ORMAN GARDEN: WHAT HAPPENED TO ITS IDENTITY AND WHY?}

\section{Contextual perspective}

Orman garden was built to compliment the new Cairo identity and to symbolize modernization and westernization similar to its European counterparts, especially France, as the garden design was inspired by "Bois de Boulogne" in Paris. The garden was created by a French horticulturist and landscape architect (Barillet de Deshamps) in 1873 in the era of the Khedive Ismael (Cultnat, 2018). Khedive Ismael was the leader of the 'green revolution' in Cairo city; his vision pursued the establishment of green corridors as Shobra boulevard and gardens in the city as (Azbakia, Asmak, Zoo). The Orman garden was originally created to provide the royal palaces with citrus fruits; now it is a public botanical garden located near the Nile River and adjacent to Cairo University (Figure 1).

\section{Fig. 1: Orman Garden location in Cairo city}

Source: Research

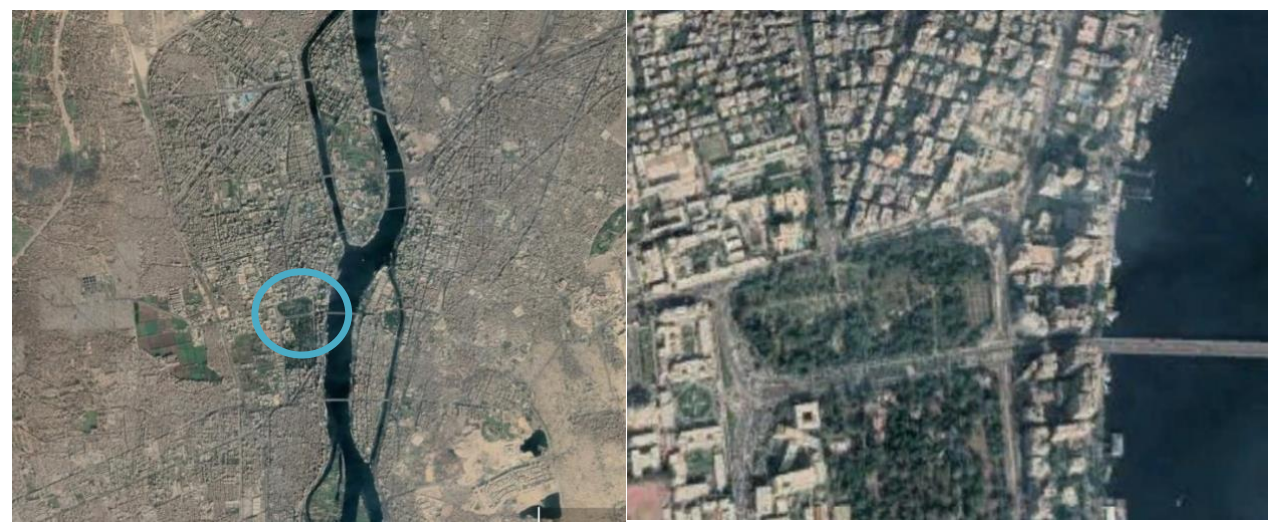


Fig. 2: Orman garden area evolution from 1973 till 2019

Source: Researcher

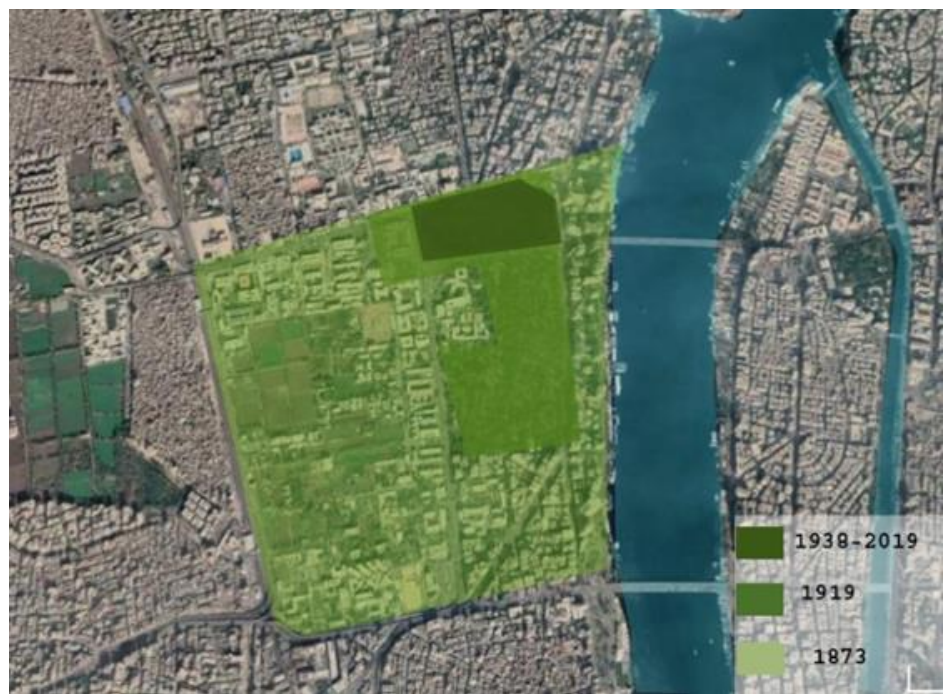

\section{Orman garden identity transformation}

The garden original identity 1873-1918

The garden was originally a part of the "Giza Palace Complex" (Figure 2). The complex included three palaces with an area of 210 hectares (garden added) (Figure 3). The palace garden comprised lakes, wooden pergolas, colored gravel paths imported from Greece, trees, plants brought from all over the world, rare bird and animal cages (Figure 4), and was used to welcome Khedive Ismael guests (Labib \& Hamdy, 2004). The garden was a symbol of the new vision set for Cairo city by Khedive Ismael, and an icon of his power and wealth. Before the main palace was destroyed it was used as a museum.

\section{Fig. 3: The location of Giza Palace gardens}

Source:(Cultnat, 2018)

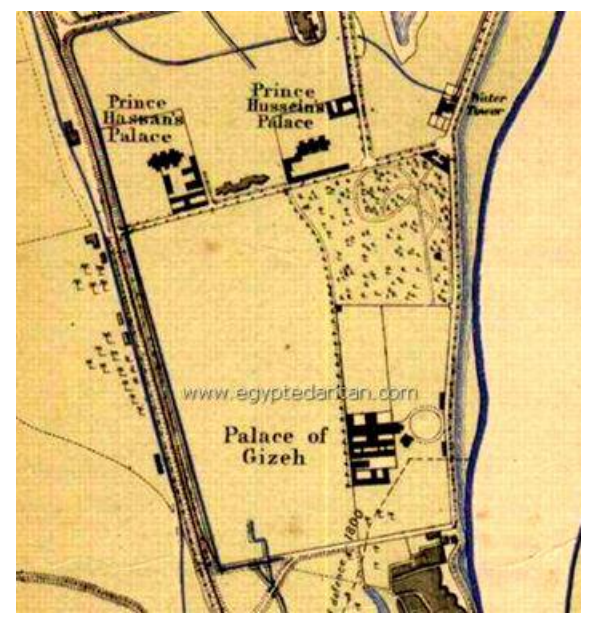


Abd El Aziz N.: Historic identity transformation in cultural heritage sites the story of Orman historical garden in Cairo city, Egypt

Fig. 4: The original features of Orman garden

Source: Abd El Rahman, 2016 and Shebl, 2012
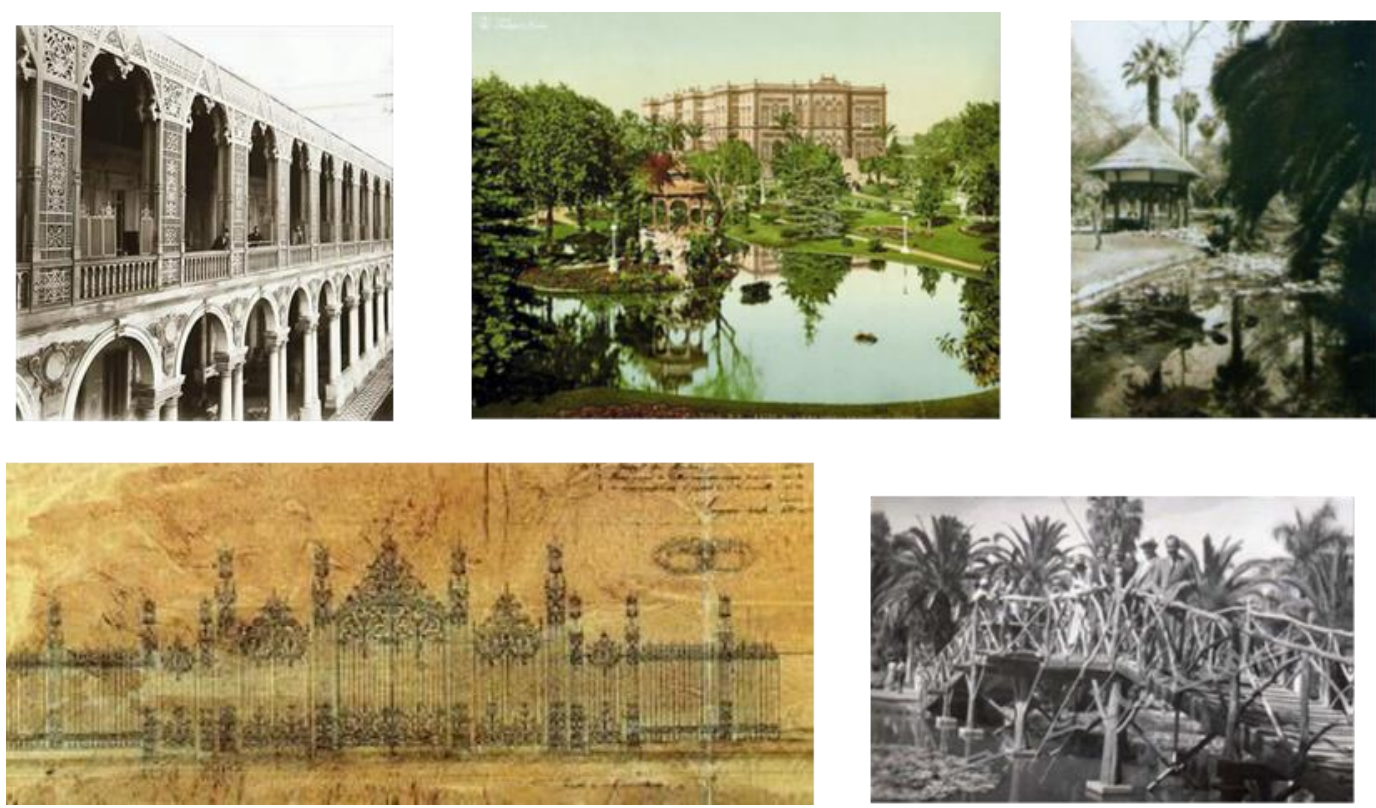

Fig. 5: The Orman garden in 1919

Source: Researcher after Nabil, 2009

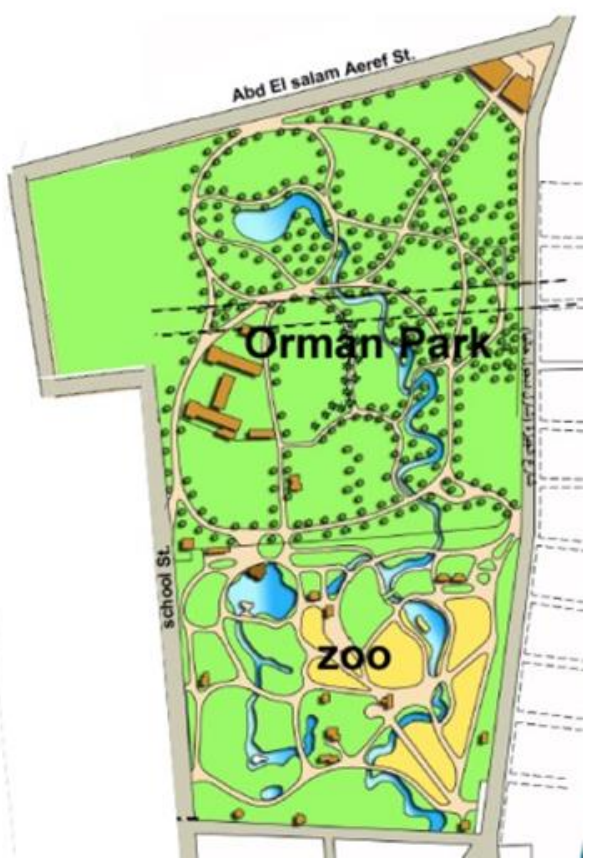


The garden identity 1919-1937

The political scene changed drastically, in 1919 Zaghlol led a revolution to liberate the country from the British dominance; in this period Giza gardens were dismantled into many parts. In 1928 Princes Fatima (a member of the royal family) donated a piece of the Giza gardens to build the Egyptian University, afterward, it was named Foud the First University (now Cairo University). As for the Orman garden, it was handed to the Ministry of Agriculture in 1919 where it became 24.3 hectares (Figure 5). The garden still preserved its original features and became a botanical garden with some animal cages, the public was allowed to access the garden with unrecognizable fee.

\section{The garden identity 1938-2010}

From 1938 to 2010 the country underwent various structural, economic, and political changes. The Royal regime collapsed, and the republic presidency began, staring with Abd El Nasser then El Sadat then Mobarak. Cairo, in this duration, witnessed a rapid increase in population and the need to expand the city infrastructure. A new arterial was created in Cairo city to connect "Manial district" to Cairo University in 1938. The new arterial (Nahda Street) penetrated the Orman garden to slice it into two gardens, the botanical garden, and the zoo, and the area decreased to reach 11.76 hectares (Figure 6).

\section{Fig. 6: The garden after it was separated from the Zoo and other uses were added}

Source: Researcher on a map from Survey of Egypt, 1929

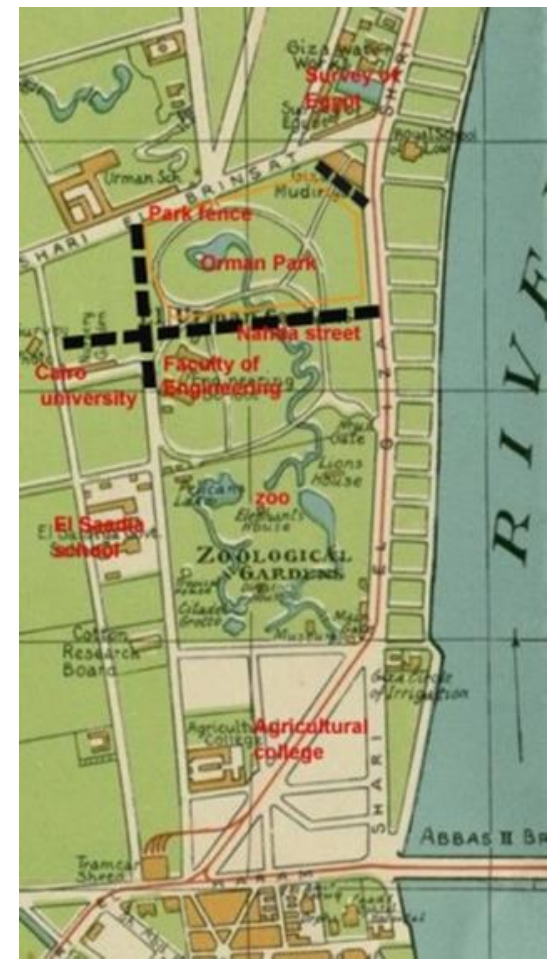

The uncontrolled urbanization continued; consequently, the garden lost the northeast part to the Giza Security Department and the eastern region to expand the university entrance. These alterations drastically impacted the physical features of the garden. The buildings 
Abd El Aziz N.: Historic identity transformation in cultural heritage sites the story of Orman historical garden in Cairo city, Egypt

which were added in the garden in Abd El Naser era reflected his State Socialism Policy in the architectural characteristics. More facilities (toilets, cafeteria, administration, mosque, library) manifested to serve the growing demand, however on the bright side all socio-economic standards used the garden at that time. Starting from 1980 liberalization policies and Free Enterprise Economy were adapted in Mobarak era. By time the country's economy was under stress resulting in neglecting the importance of open green spaces in the city; unfortunately the historic gardens faced the same fate. Local municipal started encouraging generating internal revenues. The garden embarked the renting policy (open area for kids, hosting a flower show) to survive. The flower show is held annually in March for 45 days, where nurseries and landscape companies gather to promote their services. It is considered an important event; nonetheless, it posts an enormous pressure on the garden quality. In addition to the shift in the socio-economic standard of users from all incomes to middle - low-income users. By time, the garden deteriorated and lost many of its diacritical features either due to poor maintenance or unprofessional interventions, transforming the place into a municipal garden with no character.

\section{The Garden identity 2011-2019}

Orman garden was used as a protesting venue in the 2011 revolution; it is safe to say that this was the most challenging event in the modern era affecting the garden quality. In that time the garden was totally damaged, vegetation suffered the most. The herbarium was stolen, which included documentation of the plants and seeds, and King Farouk I private collections of wild and medicinal plants (Shebl, 2012). Therefore, after breaking up the protest, the government started a renovation process. Although the renovation was in good intentions, it resulted in deforming the garden identity, the physical features were altered, and new hybrid features as seats and materials were enforced as interlocking pavers, new internal iron fences, and concrete benches (Figure 7). New plants were added not related to the original species. Currently, the garden hosts 835 species cultivated in 12 sections; they are the rock garden that contains over 200 species of Cactus and succulents, the rose garden, the water pond containing water plants, and multi greenhouses (Abd El Ghany, 2007). The other sections are for coniferous trees and palms (Figure 8). 
Fig. 7: Alteration in the physical garden design

Source: Researcher

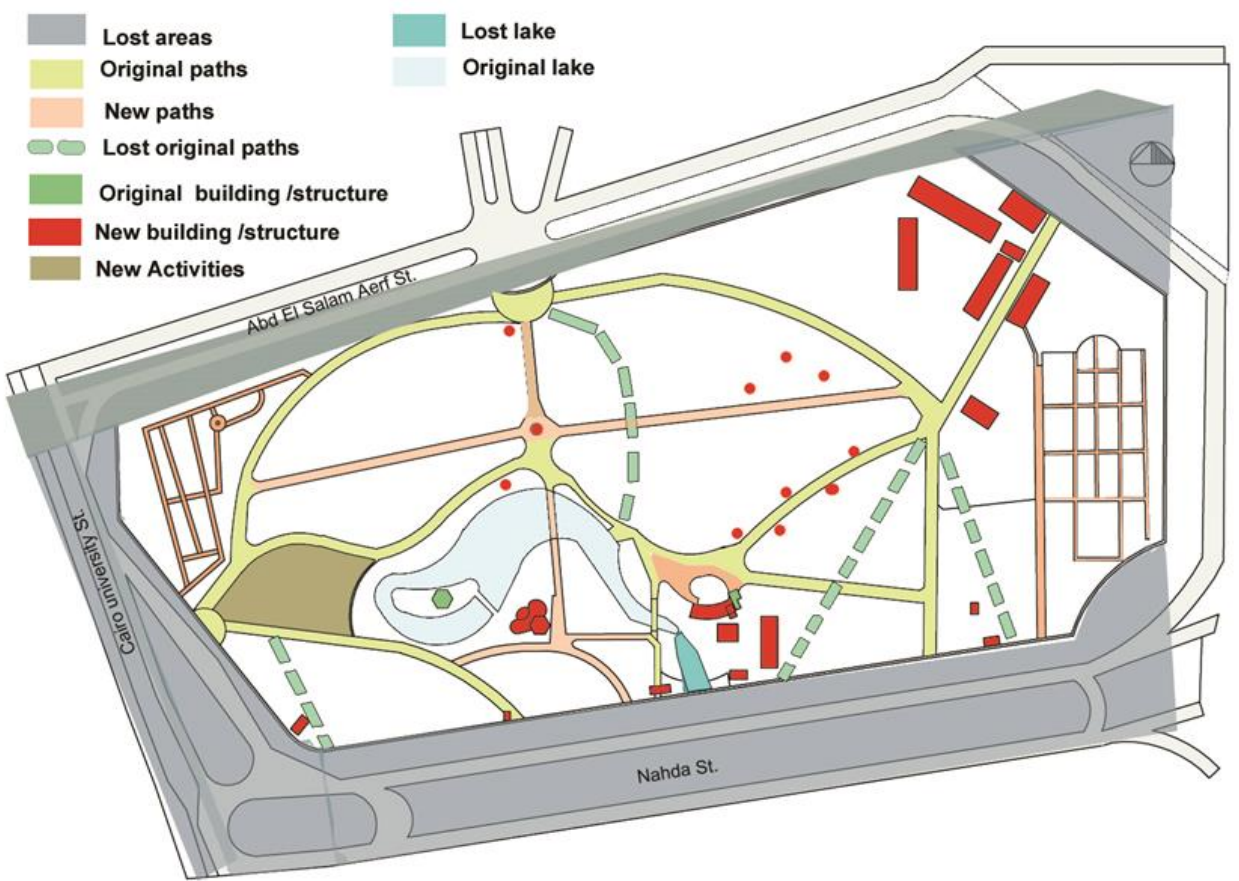

Fig. 8: Orman garden design and plant distribution

Source: Researcher After NOUH, 2013 and Egyptian agricultural museum, 2006

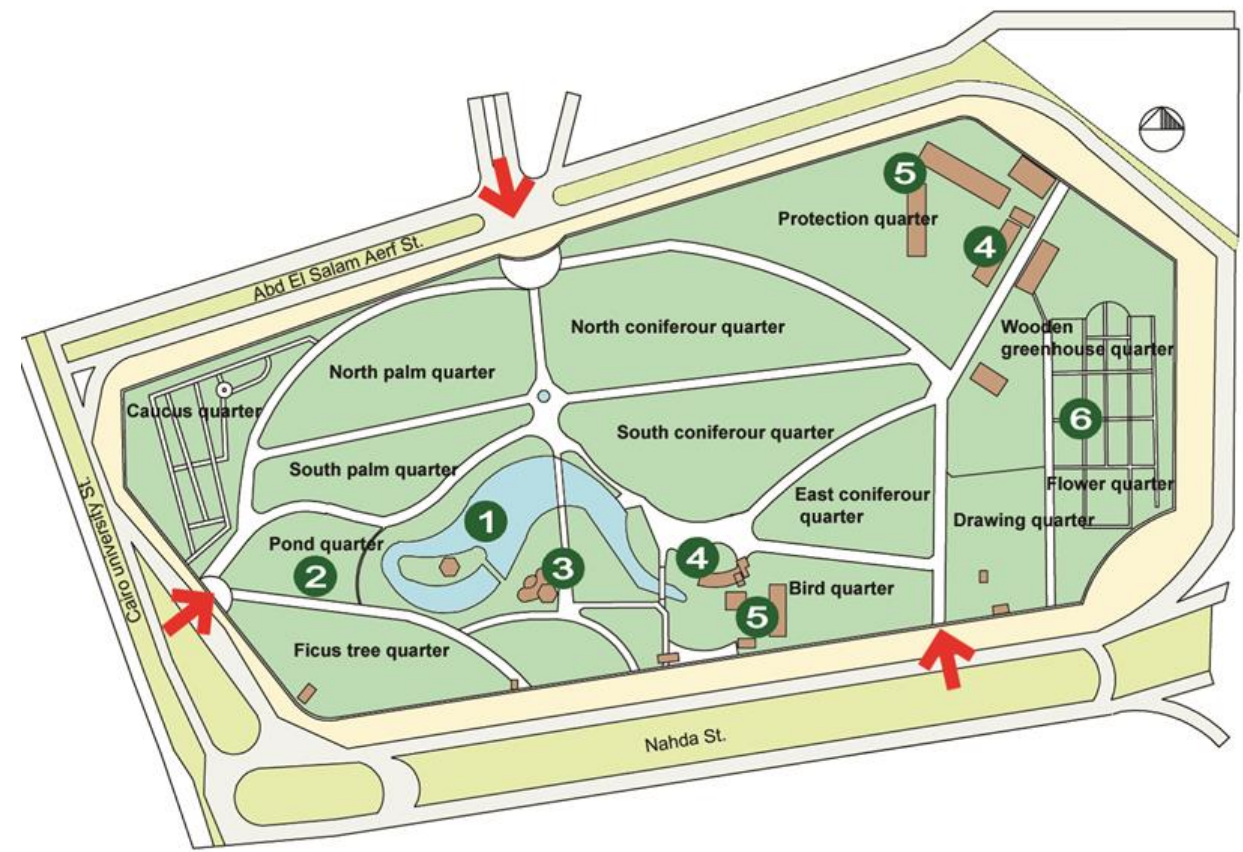




\section{RESULTS}

After analyzing the history of Orman Garden starting from 1873 till 2019, the findings affirm that the garden identity transformed rigorously in 1938 when urbanization devoured a large area of the garden. The original aim of the garden was educational and horticultural; it documented collections of living plants for scientific research, conservation, display, it sought to preserve plants and host exotic species. The preceding mentioned role was partially lost, as rare species disappeared and were replaced by other new ones, nevertheless the variety of species increased, however, the uniqueness decreed, as well as the distinction between ancient trees or other new vegetation is missing. The garden lost most of its original design due to deductions, for example, the unique physical elements borrowed from the French garden vanished, as music kiosks, bridges, seats, and the original fence. New features were added to the garden like light poles, benches, waterfalls, cast-iron fences, concrete curbs that contradict with the original designs, in addition to the use of new material in the hardscape (interlock/asphalt instead of loose gravel and compacted soil). The organic plan is interrupted by new formal axis to facilitate moving around the place (Figure 9).

As for the activities, the garden started as a botanical garden where education, breading plants, strolling and relaxing were the main activities, by time, the active recreational role dominated, and the garden identity is commercialized to the extent that it is known and treated as a public park more than a historic venue.

The garden meaning changed from a botanical oasis hosting endangered, rare, and exotic species and welcoming all socio-economic standards, especially high-income dwellers, to a public garden serving the needs of low-income users. The old generation visitors (in the 60s $\& 70$ s) declared that they remember the garden as a quiet place to spend the weekends and enjoy the lash planting, bird sounds, and watching swans in the lake. The garden represented a living witness of the royal era in the Egyptian history.A grandmother added that "The place was used to shoot movies". As for the current users, $88 \%$ stated that they used the garden for entertainment purposes (playing, strolling, meeting friends), acknowledging its horticultural function then again ignoring its historical value. $22 \%$ mostly college students knew its history but expressed their disappointment with its disfigured character. College students see the garden as a place to rest after lectures.Regarding other groups the garden manager pointed out that students of the Faculty of Agriculture visit the garden for educational and research purposes, in addition to occasional users seeking to explore the flower exhibition and few school trips Due to the transformation of the garden role in the city, the activities evolved to meet the demands of modern life like cafeterias, kid's area, and kiosks. All interviews with the maintenance staff pointed out complaints from the visitors' behaviors particularly teenagers, either for lettering the place or vandalizing trees and other site furniture.

Now, the most critical question, what led to this deteriorated situation? As well recognized, a complicated problem never has a simple answer. Results indicate that globalization did not participate in the garden identity loss, as the changes were more affected by local economic, political, social forces more than international trends. 
Fig. 9: The current situation in Orman garden

Source: Researcher

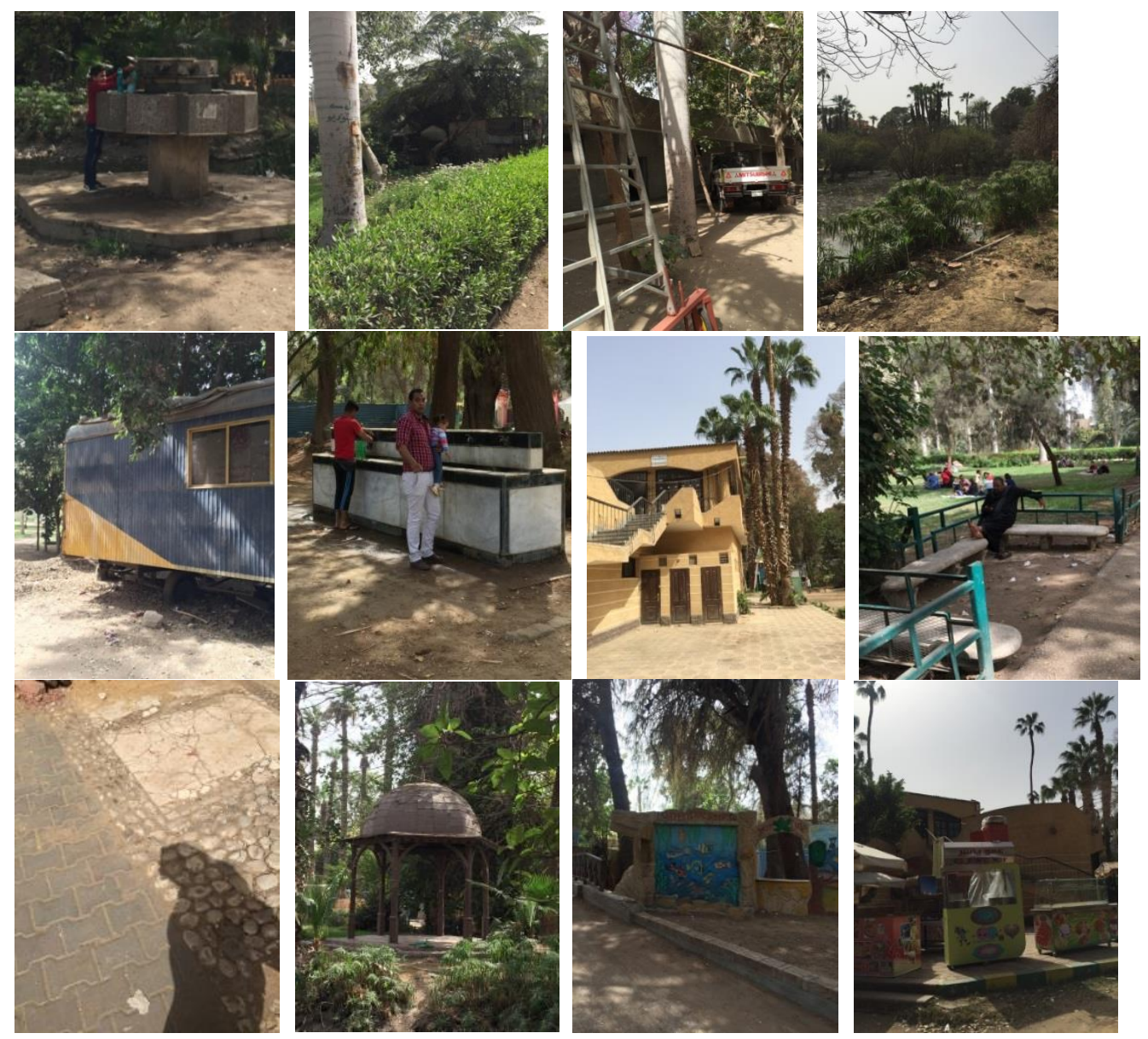

Then what are the main forces behind losing the historical identity? The institutional system is to be blamed mainly, as it abandoned the historic gardens defenseless with no law protection, that facilitated the invasion either by deduction or replacing valuable elements representing the place identity. The centralist and hierarchical planning and design approaches of the local authorities in Egypt have excluded the public from the decision-making processes of heritage sites, depriving the garden of civil protection. Urbanization and the increase of population due to immigration from rural regions to the city provoked the shrinkage of open green spaces, which added tremendous pressure on historical gardens in general and on Orman garden specifically. To clarify this pressure, the garden exceeds its carrying capacity during the flower show and official holidays as visitors may reach more than 20.000 per day, vehicles are allowed to enter the garden, plants are vandalized, displayers add random permanent waterfalls each year, and no penalties are enforced. All the foregoing impacts directly the physical appearance and the activities in the garden hence its identity (Figure 10).

The economic situation did not aid. The country faced many wars and economic stresses that led to downsizing the budget and attention towards open green spaces in principal. The 
lack of sufficient funding led to low maintenance and shortage in repairing the unique collapsing elements, which resulted in the loss of its historic flavor. The balance between generating income and preserving the quality of the garden was and still is missing. For example, despite the fact that the annual flower show sabotages the garden, it is highly appraised by local authorities for providing income.

Furthermore, the shift in social ideologies influenced the activities and the meaning of the garden. When the social stratification upsurged in the 1980s it influenced the type of users visiting public gardens. Rich people chose to segregate themselves and recreate in private clubs while public gardens became labeled for" poor people." Thus, less educated visitors with different behaviors occupied the historic gardens causing vandalism, or unintentional harm. The high stander society deprecated the deteriorated gardens and refused to mingle with other social strata and the garden became famous for the flower show and the feast days.

Fig. 10: The flower show and seasonal feasts impact on the garden identity Source: Researchers

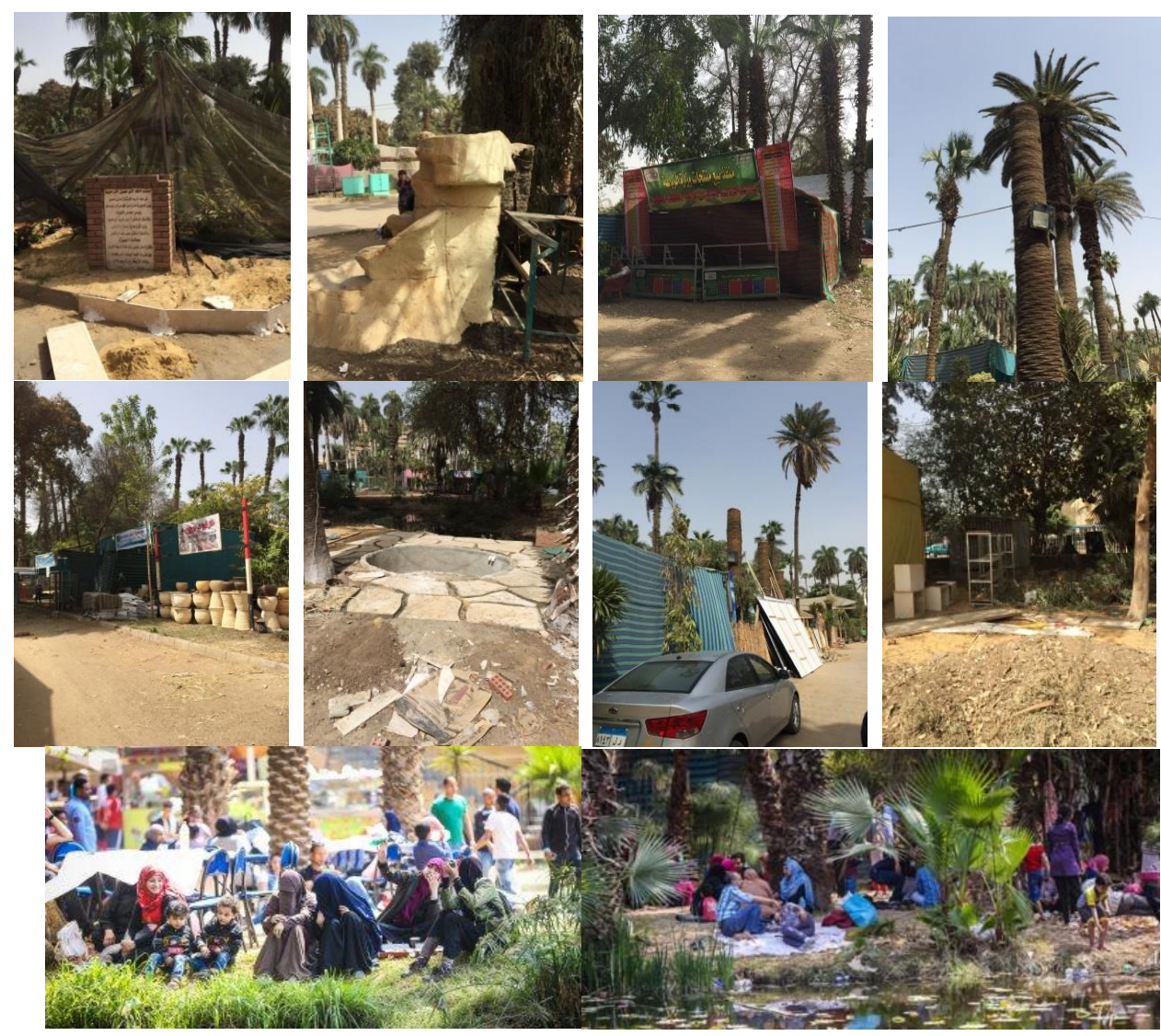




\section{DisCUSSION AND CONCLUSIONS}

Focusing on the issues of place identity in historic gardens in metropolitan cities as Cairo City, Egypt, this research found that "Orman garden" a historical botanical garden identity trajectory has transformed and has been shaped mainly by local forces, not global effects. The garden's physical characteristics, intrinsic values, and meaning were lost while activities have evolved. In every historical temporality, the garden identity changed with spatial, political-economic, and social contexts. The study shows that the garden renovation did not respect the authentic cultural and historic values/ symbols resulting in compromising and eroding the garden identity, in addition to presenting new symbols, which aggravated the situation. Since the 1980s the garden has re-configuring its identity in a destructive matter shaped by a refutation of the original built form, activities, and symbols, while a new role emerged to cope with new demands and the lack of recreational green spaces in the city, overshadowing its historical value.

The changes in the identity of Orman Garden are consistent with other gardens in Egypt like Maryland garden and other gardens in Alexandra (Shetawy \& Dief-Allah, 2013; Abd El Rahman, 2016); as well as "Gençlik Garden" in Ankara, Turkey, which suffered the same identity transformation by the effect of local and global trends. The current garden scheme has neither mummified nor completely eradicated its historical value (Ercan, 2017). Another example is illustrated by Berjman (2002) in "the Argentina Historical Gardens". Those parks suffer from the loss of their original designs, incorrect maintenance, improper uses, ineffective organization of government agencies responsible for public promenades, and the lack of supporting legislation, which is very similar to the Egyptian case. Unlike their counterparts in European cities, gardens like "Kew botanical garden" and "Berlin Botanical garden" were able to sustain their identity and accommodate new demands.

This study concluded that conserving the historic gardens needs to preserve the garden invariant value and to provide possibilities to embrace new alteration as long as it does affect the park identity, paving the path to formulating new layers which can be historic in the future. Layers ought to be distinguished to retain authenticity. Municipal administrators, no doubt, must be responsible for applying this concept, starting by introducing adequate protective legislation at national, provincial, and municipal levels. Engaging specialists with extensive experience in heritage protection and conservation theories and practices is critical to avoid what happed in Orman garden when non-professional contractors renovated the garden. An effort is needed to prepare a scientific Historical Gardens Inventory to record the original status of historical gardens and their development through time.

Regarding the conflict between providing venues for recreation and preserving the historical significance, this issue can be resolved through two approaches. The first approach is to offer alternatives for outdoor recreation by providing new parks that would lessen the pressure on historic gardens. The second approach is developing a tailored master plan for each historic garden. The master plan would determine the appropriate number of visitors, duration of stay, type of visitors, and the compatible activities, according to the garden's fragility and cultural value. Authorities need to enforce protocols to regulate the influence of users on the gardens and spread awareness towards the significance of cultural heritage.

As for resolving the conflict between the historical value and proving funding resources, it is suggested to adopt new "optimum viable uses and activities" that are capable of generating funds, while safeguarding the garden identity. Thus, it is recommended to resurrect the original recreational activities like strolling and relaxing. Besides, the garden should fulfill its original function and serve as centres of bank of important plants, preserve rare species, train arborists and collaborate with universities to research environmental biology. The garden program may include educational programmes to create environmental awareness and 
Abd El Aziz N.: Historic identity transformation in cultural heritage sites the story of Orman historical garden in Cairo city, Egypt

gardening lessons provided that their impact on the garden is studied. The previous scientific activities can be planed to generate money for the park operation. Moreover, the fund can be supplied by NGOs interested in conserving historical gardens, research centers, and donations. In the end all stakholders need to unite to defend the historic park and prevent them from being just memory in our history.

\section{REFERENCES}

Abd El Aziz, N. (2012). Designing and Managing Urban Gardens to Improve the Quality of Life in the Egyptian Cities. PhD, Cairo University, Cairo, Egypt.

Abd El Ghany, M., Hamdy, R., Youssef, L. and El-Sayed, M. (2007) The Floristic Composition of Some Historical Botanical Gardens in The Metropolitan of Cairo, Egypt. African Journal of Agricultural Research, Vol. 2 (11), Pp. 610-648.

Abd El Rahman, N. (2016). Egyptian Historical Gardens, Authenticity VS Change in Cairo's Cultural Landscape, Social and Behavioral Sciences 225, p.381-109.

Alexandrakis, G., Manasakis, C. and Kampanis, N. (2019). Economic and Societal Impacts on Cultural Heritage Sites, Resulting from Natural Effects and Climate Change, Heritage journal, Voluom 2, p. 280-305

Ashworth, Gregory J., and B. Graham (2005). Senses of Place: Senses of Time. Aldershot, Burlington:Ashgate.

Beyhan,S. and Gürkan, U. (2015). Analyzing The Relationship Between Urban Identity And Urban Transformation Implementations In Historical Process: The Case Of Isparta , International Journal Of Architectural Research. Volume 9 - Issue 1, p.158-180.

Berjman, S. (2002). Historic garden and cultural landscape ,ICOMOS, Argentina

Brill, K. (2016). Historic Preservation as a Representation of National Identity: The Cases of Colonial Williamsburg and Old San Juan, Architectural Studies Integrative Projects, Connecticut College. Paper 76.

Carmona, M., Tim, H., Taner, O., and Steve, T. (2010). Public Places-Urban Spaces. 2nd ed. Oxford: Architectural Press.

CULTNAT (2018). Orman Digital Map, About The Garden.

De Rosa, F. and Di Palma, M. (2013) Historic Urban Landscape Approach and Port Cities Regeneration: Naples between Identity and Outlook Sustainability 5, p. 4268-4287.

Egyptian Agricultural Museum (2006). An Index For Egyptian Botanical Gardens, Strategies for Botanical Gardens, The First International Conference, Giza (In Arabic).

English Heritage (2008). Conservation Principles, Policies and Guidance for The Sustainable Management of The Historic Environment.

Ercan, M. (2017). Evolving or lost identity of a historic public space? The tale of Gençlik Garden in Ankara, Journal of Urban Design, 22:4, 520-543.

Fairfax County (2019). Historic Preservation vs. Heritage Conservation. WHAT DO THESE TERMS MEAN? Virginia . USA

Florek, M., Insch, A., and Gnoth, J. (2006). City Council websites as a means of place brand identity communication. Place Branding. 2 (4): 276-296.

Gustafson, P. (2001). Meaning of Places: Everyday Experience and Theoretical Conceptualizations. Journal of Environmental Psychology. 21,P. 5-16. 
Goldfrank, A. (1991). Bringing New Life To Historic Urban Gardens: Identifying The Key Elements of The Restoration Process, Theses (Historic Preservation), University of Pennsylvania.

Guoping, W. (2014). Conserving Historic Urban Landscape And Beautifying The City By Means Of Its History, Conservation Science In Cultural Heritage, Italy

Haaland, C., \& van den Bosch, C. K. (2015). Challenges and strategies for urban green-space planning in cities undergoing densification: A review. Urban For. Urban Green., 14(4), 760-771. https://doi.org/10.1016/j.ufug.2015.07.009.

Handal, J. (2006). Rebuilding City Identity Through History: The Case of Bethlehem-Palestine. In Designing Sustainable Cities in the Developing World, edited by Georgia Butina Watson and Roger Zetter (pp. 51-68). Abingdon, Oxon: Ashgate.

Haruna, N. ,Mansora, M. and Saidb, I. (2015). Place rootedness suggesting the loss and survival of historical public spaces, Environmental Sciences 28 P. 528 - 537.

Historic England (2018). Maintenance, Repair and Conservation Management Plans.

ICOMOS (2018). The Florence Charter.

Kaymaz, I. (2013). Urban landscapes and identity. Advances in landscape architecture Rijeka, Croatia. http://dx.doi.org/10.5772/55754.

Knox, Paul L. (1984). Styles, Symbolism and Settings: The Built Environment and Imperatives of Urbanised Capitalism." Architecture et Comportment 2: 107-122.

Knox, P., and Pinch, S. (2010). Urban Social Geography: An Introduction. 6th ed. Essex: Prentice Hall.

Labib, T., and Hamdy, R. (2003). Historical Gardens In Egypt, Ministry of AgricultureOrman Garden (In Arabic).

Lowenthal, D. (1985). The Past is a Foreign Country. Cambridge: Cambridge Press.

Lynch, K. (1960). The Image of the City. Cambridge, MA: MIT Press.

Montgomery, J. (1998). Making a city: Urbanity, vitality and urban design. Urban Design, 3(1), 93-116. http://dx.doi.org/10.1080/13574809808724418.

Nabil, Y. (2009). Preservation of Historic Gardens : A Methodology for the Preservation of Historic Gardens \& Cultural Landscapes, Master Thesis, Faculty of Urban \& Regional Planning, Cairo University (In Arabic).

Nasser, N. (2003). Planning For Urban Heritage Places: Reconciling Conservation, Tourism, and Sustainable Development, Journal of Planning Literature 17(4), pp: 267-279.

National Garden Service (2018). Four Approaches to the Treatment of Historic Properties, Technical Preservation Services, US Department of Interior.

NOUH (2013). Orman Historical Garden. A Plan To Restore The Oram Garden (In Arabic).

Ouf, A., (2001). Authenticity and the Sense of Place in Urban Design, Journal of Urban Design 6(1), pp: 73-86.

Pieterse, Jan Nederveen (2006). "Globalisation as Hybridization.” In ed. by Meenakshi Gigi Durham and Douglas M. Kellner, Media and Cultural Studies (pp. 658-681). Oxford: Blackwell Publishing.

Punter, J. (1991). Participation in the design of urban space. Landscape Design, 200(1), 24-27.

Relph, E. (1976). Place and placelessness. London, UK: Pion. 
Abd El Aziz N.: Historic identity transformation in cultural heritage sites the story of Orman historical garden in Cairo city, Egypt

Shebl, D.(2012). A Sustainable Approach to Perverse The Historical Gardens In Egypt. Doctoral Thesis, Architecture Department, Monofia University, Egypt (In Arabic).

Shetawy, A. and Dief-Allah, D. (2013). Historic Gardens in the Face of Change: The Merryland Garden, Cairo, Egypt, SB13-Cairo 2013, p. 288-303.

Sonia, B., and Tanasescu, I. (2013). Restoration and Conservation of Gardens, Gardens and Historic Landscapes In Terms of Multidisciplinary Guidelines, Agricultura - Ştiinţă şi practică $n r .1$ - 2 (pp. 85-86). Survey of Egypt (1929). Orman and Zoo map.

Ujang, N. (2012). Place attachment and continuity of urban place identity. Procedia -Social and Behavioral Sciences, 49, 156-167. http://dx.doi.org/10.1016/j.sbspro.2012.07.014.

Williams, R., Patterson, E., Roggenbuck, W., Watson, E. (1992). Beyond the Commodity Metaphor: Examining Emotional and Symbolic Attachment to Place. Leisure Science. 14, 29-46.

Ziyaee, M. (2018). Assessment of urban identity through a matrix of cultural landscapes, Cities, p. 21-31. 